\title{
Numerical investigation of flow distribution in tubular space of fin-and-tube heat exchanger
}

\author{
Tomasz Stelmach ${ }^{1}$ \\ ${ }^{1}$ Institute of Thermal Power Engineering, Cracow University of Technology, Faculty of Mechanical Engineering
}

\begin{abstract}
This paper presents the experimental and numerical investigation of flow distribution in the tubular space of cross-flow fin-and-tube heat exchanger. The tube bundle with two rows arranged in staggered formation is considered. A standard heat exchanged manifold, with inlet nozzle pipe located asymmetrically is considered. The outlet nozzle pipe is located in the middle of the outlet manifold. A developed experimental setup allows one to measure volumetric flow rate in heat exchanger tubes using the ultrasonic flowmeters. The measurement results are then compared with CFD simulation in ANSYS CFX code using the SSG Reynolds Stress turbulence model, and a good agreement is found for tube Re numbers varied from 1800 to 3100 .
\end{abstract}

\section{Introduction}

Heat exchangers with finned elliptical tubes are widely used in industry, i.e., chemical, petrochemical, energy and automotive industries [1-4]. The main advantage of using those devices is the large heat transfer area in a compact shape. Mostly, the elliptical tubes are used for tubular space of heat exchanger due to the lower pumping power needed from the intertubular space side $[13,14]$. However, due to the compact shape of fin-and-tube heat exchangers, there may exist a problem of flow maldistribution to heat exchanger tubes [1,5-8]. The reason is the small volume of heat exchanger manifold. The flow maldistribution in heat exchanger tubes may result in high thermal stresses $[11,12]$, as well as flow boiling $[9,10]$ in a region where the flow rate is low. In literature, the flow maldistribution is heat exchangers is not studied extensively. Mostly, the simulation works are performed. However, the number of experimental works is insufficient. Therefore this paper presents an experimental stand for investigation of flow maldistribution in tubular space of fin-and-tube heat exchanger. The experimental results are obtained for various flow rates, set at the inlet tu heat exchanger. The results of experiments are compared with the CFD simulation results to check the correctness of CFD code ANSYS CFX.

\section{Experimental setup}

The experimental setup consists of the storage tank (1), from which the water is pumped (2) through connection pipes (4) to heat exchanger. The total volumetric flow rate is controlled via the flow meter (3). The inlet manifold (5) is made of steel pipe with an external diameter of $115 \mathrm{~mm}$ and a thickness of $6 \mathrm{~mm}$. The inlet nozzle can be positioned in the various location of heat exchanger manifold. In this study, it is assumed that the distance from one side of the manifold to the inlet nozzle pipe axis is $455 \mathrm{~mm}$ while $200 \mathrm{~mm}$ from the other side. The outlet manifold nozzle pipe is located in the middle of the manifold (8). The tubular space (6) of heat exchanger consists of two rows of elliptical tubes arranged in a staggered formation with 10 tubes per row. The Sontex Superstatic 749 flowmeters (7) are installed in all tubes at the distance of $300 \mathrm{~mm}$ before the outlet manifold. The flowmeters allow one to measure the volumetric flow rate in each tube of the heat exchanger. The measurement data is collected through the dedicated data acquisition system.

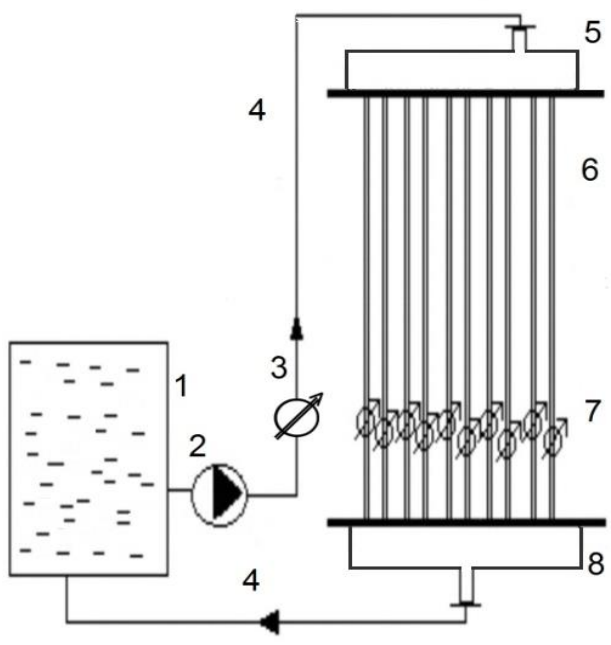

Fig. 1. Scheme of the experimental setup for the investigation of flow conditions in a tubular space of fin-and-tube heat exchanger: 1 - water feed tank, 2 - pump, 3 - flow meter of total volumetric flow rate, 4 - connection pipes, 5 - inlet manifold with a nozzle pipe, 6 - tube bundle, 7 - flow meters for volumetric flow rate in each tube, 8 - outlet manifold with an outlet nozzle pipe.

\footnotetext{
Corresponding author: tomasz.stelmach@gkpge.pl
} 


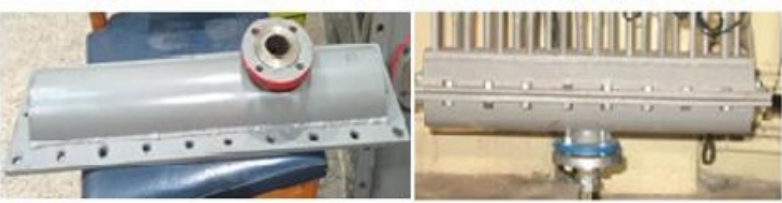

Fig. 2. Inlet and outlet manifold of the tested heat exchanger.

Figure 2 shows the inlet and outlet manifold of the tested heat exchanger. To ensure uniform inflow of the water the straight connecting pipe with the length of 100 $\mathrm{mm}$ is installed above and below the inlet and outlet nozzle pipes.

\section{Measurements of flow distribution in heat exchanger tubular space}

The major geometrical dimensions of the heat exchanger inlet and outlet manifolds are shown in Fig. 3. The nozzle pipe in the tested inlet manifold is located $455 \mathrm{~mm}$ from the left side of the inlet manifold, and $200 \mathrm{~mm}$ from the right side.

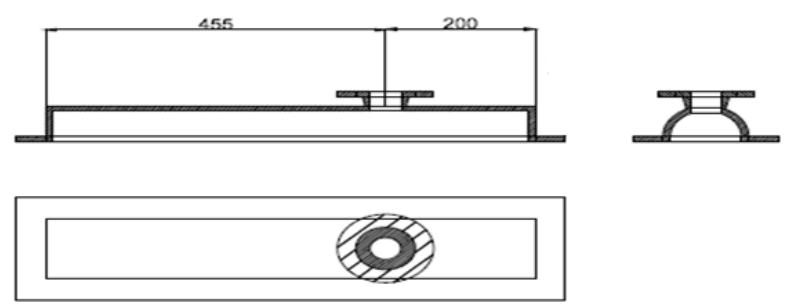

Fig. 3. Dimensions of the inlet manifold.
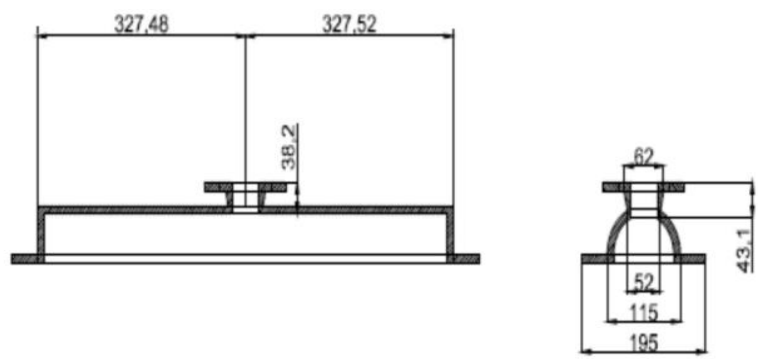

Fig. 4. Dimensions of the outlet manifold.

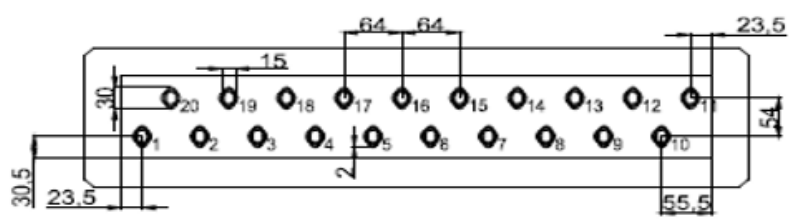

Fig. 5. Scheme of the sieve plate with given tube numbering.

In this study, the measurements are performed for the total volumetric flow rate in a rage from $3 \mathrm{~m}^{3} / \mathrm{h}$ to $5 \mathrm{~m}^{3} / \mathrm{h}$. That volumetric flow range corresponds to the transitional and turbulent flow regime. The results are presented for the tubes in the first row of tube bundle 1-10 and the second row of tube bundle 11-20. The water temperature is constant and equal to $20{ }^{\circ} \mathrm{C}$. The readings from the flowmeters were made after the steady-state conditions were achieved.
Measurement no 1 - total volumetric flow rate of $\dot{V} \approx 3$ $\left[\mathrm{m}^{3} / \mathrm{h}\right]$ :

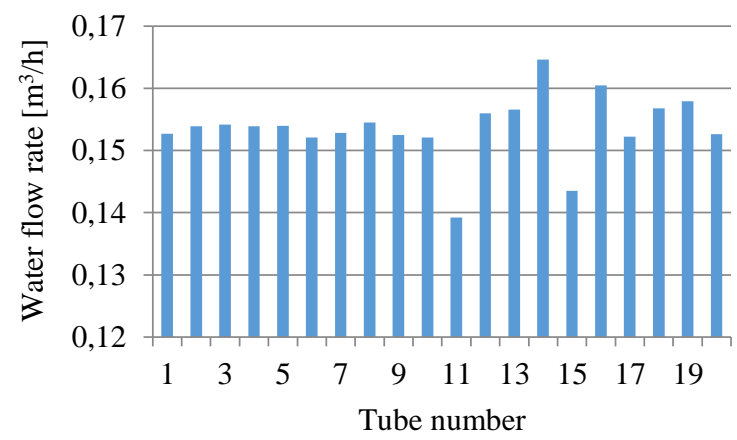

Fig. 6. Volumetric flow rate in heat exchanger tubes for a total flow rate of $\dot{V}=3,0726\left[\mathrm{~m}^{3} / \mathrm{h}\right]$.

Table 1. The volumetric flow rate and Reynolds (Re) numbers in heat exchanger tubes for a total flow rate of $\dot{V}=3,0726$ $\left[\mathrm{m}^{3} / \mathrm{h}\right]$.

\begin{tabular}{|c|c|c|c|c|c|}
\hline Tube no. & $\mathbf{1}$ & $\mathbf{2}$ & $\mathbf{3}$ & $\mathbf{4}$ & $\mathbf{5}$ \\
\hline $\begin{array}{c}\text { Flow rate } \\
{\left[\mathrm{m}^{3} / \mathrm{h}\right]}\end{array}$ & 0,1527 & 0,1539 & 0,1542 & 0,1539 & 0,1540 \\
\hline $\mathrm{Re}$ & 1818 & 1832 & 1836 & 1832 & 1833 \\
\hline Tube no. & $\mathbf{6}$ & $\mathbf{7}$ & $\mathbf{8}$ & $\mathbf{9}$ & $\mathbf{1 0}$ \\
\hline $\begin{array}{c}\text { Flow rate } \\
{\left[\mathrm{m}^{3} / \mathrm{h}\right]}\end{array}$ & 0,1521 & 0,1528 & 0,1545 & 0,1525 & 0,1521 \\
\hline $\mathrm{Re}$ & 1811 & 1819 & 1839 & 1815 & 1811 \\
\hline $\begin{array}{c}\text { Tube no. } \\
\mathbf{1 1}\end{array}$ & $\mathbf{1 2}$ & $\mathbf{1 3}$ & $\mathbf{1 4}$ & $\mathbf{1 5}$ \\
\hline $\begin{array}{c}\text { Flow rate } \\
{\left[\mathrm{m}^{3} / \mathrm{h}\right]}\end{array}$ & 0,1392 & 0,1560 & 0,1566 & 0,1646 & 0,1435 \\
\hline $\mathrm{Re}$ & 1657 & 1857 & 1864 & 1960 & 1708 \\
\hline Tube no. & $\mathbf{1 6}$ & $\mathbf{1 7}$ & $\mathbf{1 8}$ & $\mathbf{1 9}$ & $\mathbf{2 0}$ \\
\hline $\begin{array}{c}\text { Flow rate } \\
{\left[\mathrm{m}^{3} / \mathrm{h}\right]}\end{array}$ & 0,1605 & 0,1522 & 0,1568 & 0,1579 & 0,1526 \\
\hline $\begin{array}{r}\text { Re } \\
\hline\end{array}$ & 1911 & 1812 & 1867 & 1880 & 1817 \\
\hline
\end{tabular}

Measurement no 2 - total volumetric flow rate of $\dot{V} \approx 3,5$ $\left[\mathrm{m}^{3} / \mathrm{h}\right]$ :

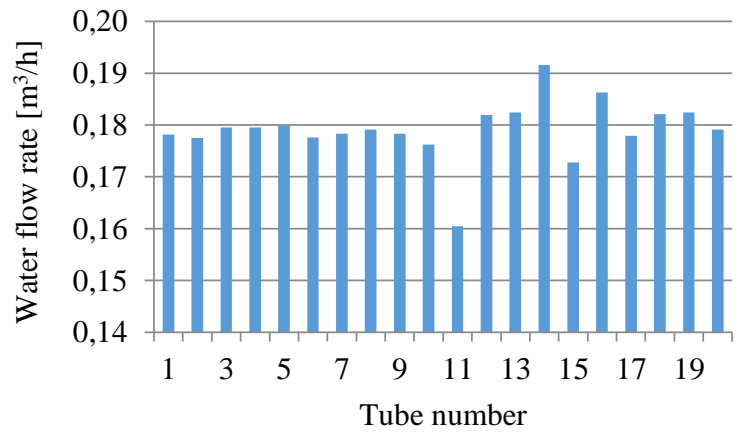

Fig. 7. Volumetric flow rate in heat exchanger tubes for total flow rate of $\dot{V}=3,5811\left[\mathrm{~m}^{3} / \mathrm{h}\right]$. 
Table 2. The volumetric flow rate and Reynolds (Re) numbers in heat exchanger tubes for a total flow rate of $\dot{V}=3,58\left[\mathrm{~m}^{3} / \mathrm{h}\right]$.

\begin{tabular}{|c|c|c|c|c|c|}
\hline Tube no. & $\mathbf{1}$ & $\mathbf{2}$ & $\mathbf{3}$ & $\mathbf{4}$ & $\mathbf{5}$ \\
\hline $\begin{array}{c}\text { Flow rate } \\
{\left[\mathrm{m}^{3} / \mathrm{h}\right]}\end{array}$ & 0,1782 & 0,1775 & 0,1795 & 0,1795 & 0,1799 \\
\hline $\mathrm{Re}$ & 2121 & 2113 & 2137 & 2137 & 2142 \\
\hline Tube no. & $\mathbf{6}$ & $\mathbf{7}$ & $\mathbf{8}$ & $\mathbf{9}$ & $\mathbf{1 0}$ \\
\hline $\begin{array}{c}\text { Flow rate } \\
{\left[\mathrm{m}^{3} / \mathrm{h}\right]}\end{array}$ & 0,1776 & 0,1783 & 0,1791 & 0,1783 & 0,1762 \\
\hline Re & 2114 & 2123 & 2132 & 2123 & 2098 \\
\hline Tube no. & $\mathbf{1 1}$ & $\mathbf{1 2}$ & $\mathbf{1 3}$ & $\mathbf{1 4}$ & $\mathbf{1 5}$ \\
\hline $\begin{array}{c}\text { Flow rate } \\
{\left[\mathrm{m}^{3} / \mathrm{h}\right]}\end{array}$ & 0,1605 & 0,1819 & 0,1824 & 0,1916 & 0,1728 \\
\hline Re & 1911 & 2165 & 2171 & 2281 & 2057 \\
\hline Tube no. & $\mathbf{1 6}$ & $\mathbf{1 7}$ & $\mathbf{1 8}$ & $\mathbf{1 9}$ & $\mathbf{2 0}$ \\
\hline $\begin{array}{c}\text { Flow rate } \\
{\left[\mathrm{m}^{3} / \mathrm{h}\right]}\end{array}$ & 0,1863 & 0,1779 & 0,1821 & 0,1824 & 0,1791 \\
\hline Re & 2218 & 2118 & 2168 & 2171 & 2132 \\
\hline
\end{tabular}

Measurement no 3 - total volumetric flow rate of $\dot{V} \approx 4$ $\left[\mathrm{m}^{3} / \mathrm{h}\right]$ :

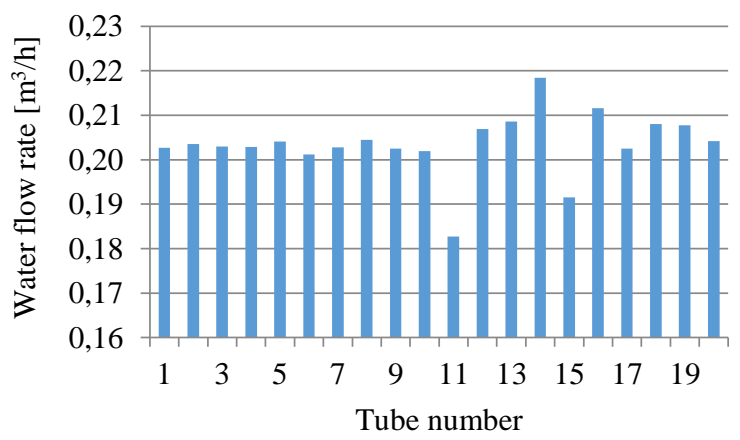

Fig. 8. Volumetric flow rate in heat exchanger tubes for a total flow rate of $\dot{V}=4,0712\left[\mathrm{~m}^{3} / \mathrm{h}\right]$.

Table 3. The volumetric flow rate and Reynolds (Re) numbers in heat exchanger tubes for a total flow rate of $\dot{V}=4,07\left[\mathrm{~m}^{3} / \mathrm{h}\right]$.

\begin{tabular}{|c|c|c|c|c|c|}
\hline Tube no. & $\mathbf{1}$ & $\mathbf{2}$ & $\mathbf{3}$ & $\mathbf{4}$ & $\mathbf{5}$ \\
\hline $\begin{array}{c}\text { Flow rate } \\
{\left[\mathrm{m}^{3} / \mathrm{h}\right]}\end{array}$ & 0,2027 & 0,2035 & 0,2030 & 0,2029 & 0,2041 \\
\hline Re & 2413 & 2423 & 2417 & 2415 & 2430 \\
\hline Tube no. & $\mathbf{6}$ & $\mathbf{7}$ & $\mathbf{8}$ & $\mathbf{9}$ & $\mathbf{1 0}$ \\
\hline $\begin{array}{c}\text { Flow rate } \\
{\left[\mathrm{m}^{3} / \mathrm{h}\right]}\end{array}$ & 0,2012 & 0,2028 & 0,2045 & 0,2025 & 0,2019 \\
\hline Re & 2395 & 2414 & 2435 & 2411 & 2404 \\
\hline Tube no. & $\mathbf{1 1}$ & $\mathbf{1 2}$ & $\mathbf{1 3}$ & $\mathbf{1 4}$ & $\mathbf{1 5}$ \\
\hline $\begin{array}{c}\text { Flow rate } \\
{\left[\mathrm{m}^{3} / \mathrm{h}\right]}\end{array}$ & 0,1827 & 0,2069 & 0,2086 & 0,2184 & 0,1915 \\
\hline Re & 2175 & 2463 & 2483 & 2600 & 2280 \\
\hline Tube no. & $\mathbf{1 6}$ & $\mathbf{1 7}$ & $\mathbf{1 8}$ & $\mathbf{1 9}$ & $\mathbf{2 0}$ \\
\hline
\end{tabular}

\begin{tabular}{|c|c|c|c|c|c|}
\hline $\begin{array}{c}\text { Flow rate } \\
{\left[\mathrm{m}^{3} / \mathrm{h}\right]}\end{array}$ & 0,2116 & 0,2025 & 0,2080 & 0,2077 & 0,2042 \\
\hline $\operatorname{Re}$ & 2519 & 2411 & 2476 & 2473 & 2431 \\
\hline
\end{tabular}

Measurement no 4 - total volumetric flow rate of $\dot{V} \approx 4,5$ $\left[\mathrm{m}^{3} / \mathrm{h}\right]$ :

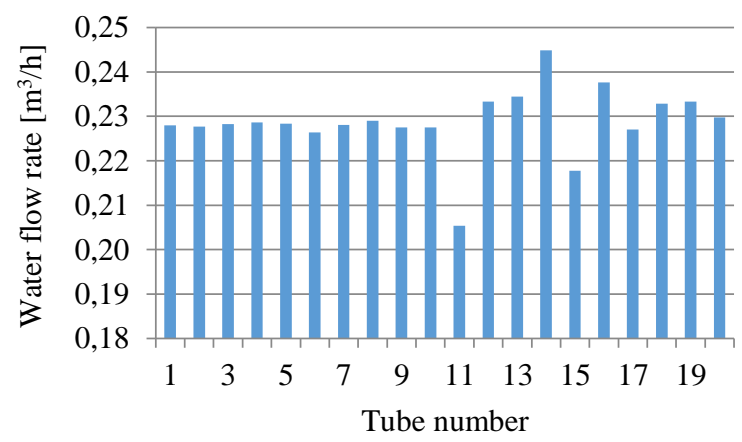

Fig. 9. Volumetric flow rate in heat exchanger tubes for total flow rate of $\dot{V}=4,5760\left[\mathrm{~m}^{3} / \mathrm{h}\right]$.

Table 4. The volumetric flow rate and Reynolds (Re) numbers in heat exchanger tubes for a total flow rate of $\dot{V}=4,5760$ $\left[\mathrm{m}^{3} / \mathrm{h}\right]$.

\begin{tabular}{|c|c|c|c|c|c|}
\hline Tube no. & $\mathbf{1}$ & $\mathbf{2}$ & $\mathbf{3}$ & $\mathbf{4}$ & $\mathbf{5}$ \\
\hline $\begin{array}{c}\text { Flow rate } \\
{\left[\mathrm{m}^{3} / \mathrm{h}\right]}\end{array}$ & 0,2280 & 0,2277 & 0,2283 & 0,2286 & 0,2284 \\
\hline $\mathrm{Re}$ & 2714 & 2711 & 2718 & 2721 & 2719 \\
\hline Tube no. & $\mathbf{6}$ & $\mathbf{7}$ & $\mathbf{8}$ & $\mathbf{9}$ & $\mathbf{1 0}$ \\
\hline $\begin{array}{c}\text { Flow rate } \\
{\left[\mathrm{m}^{3} / \mathrm{h}\right]}\end{array}$ & 0,2264 & 0,2281 & 0,2290 & 0,2275 & 0,2275 \\
\hline $\mathrm{Re}$ & 2695 & 2715 & 2726 & 2708 & 2708 \\
\hline $\begin{array}{c}\text { Tube no. } \\
\text { Flow rate } \\
{\left[\mathrm{m}^{3} / \mathrm{h}\right]}\end{array}$ & 0,2054 & 0,2333 & 0,2345 & 0,2449 & 0,2178 \\
\hline Re & 2445 & 2777 & 2792 & 2915 & 2593 \\
\hline Tube no. & $\mathbf{1 6}$ & $\mathbf{1 7}$ & $\mathbf{1 8}$ & $\mathbf{1 9}$ & $\mathbf{2 0}$ \\
\hline $\begin{array}{c}\text { Flow rate } \\
{\left[\mathrm{m}^{3} / \mathrm{h}\right]}\end{array}$ & 0,2376 & 0,2270 & 0,2329 & 0,2333 & 0,2298 \\
\hline Re & 2829 & 2702 & 2773 & 2777 & 2736 \\
\hline
\end{tabular}


Measurement no 5 - total volumetric flow rate of $\dot{V} \approx 5$ $\left[\mathrm{m}^{3} / \mathrm{h}\right]$ :

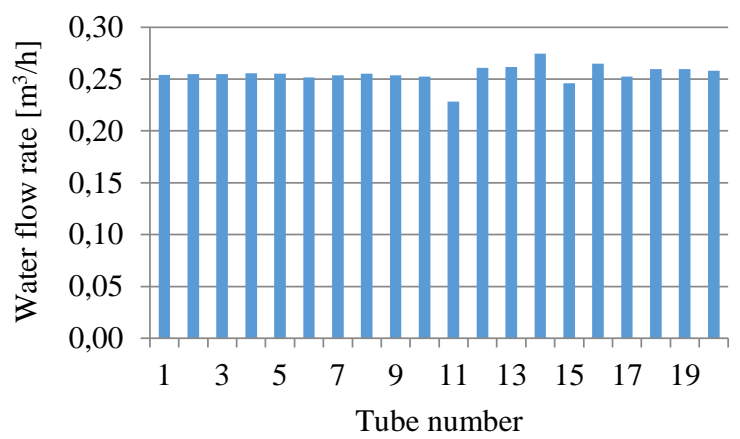

Fig. 10. The volumetric flow rate and Reynolds $(\mathrm{Re})$ numbers in heat exchanger tubes for a total flow rate of $\dot{V}=5,1073$ $\left[\mathrm{m}^{3} / \mathrm{h}\right]$.

Table 5. The volumetric flow rate and Reynolds (Re) numbers in heat exchanger tubes for a total flow rate of $\dot{V}=5,1073$ $\left[\mathrm{m}^{3} / \mathrm{h}\right]$.

\begin{tabular}{|c|c|c|c|c|c|}
\hline Tube no. & $\mathbf{1}$ & $\mathbf{2}$ & $\mathbf{3}$ & $\mathbf{4}$ & $\mathbf{5}$ \\
\hline $\begin{array}{c}\text { Flow rate } \\
{\left[\mathrm{m}^{3} / \mathrm{h}\right]}\end{array}$ & 0,2541 & 0,2547 & 0,2549 & 0,2556 & 0,2552 \\
\hline $\mathrm{Re}$ & 3025 & 3032 & 3035 & 3043 & 3038 \\
\hline Tube no. & $\mathbf{6}$ & $\mathbf{7}$ & $\mathbf{8}$ & $\mathbf{9}$ & $\mathbf{1 0}$ \\
\hline $\begin{array}{c}\text { Flow rate } \\
{\left[\mathrm{m}^{3} / \mathrm{h}\right]}\end{array}$ & 0,2518 & 0,2537 & 0,2551 & 0,2536 & 0,2524 \\
\hline $\mathrm{Re}$ & 2998 & 3020 & 3037 & 3019 & 3005 \\
\hline $\begin{array}{c}\text { Tube no. } \\
\text { Rutow rate } \\
{\left[\mathrm{m}^{3} / \mathrm{h}\right]}\end{array}$ & 0,2284 & 0,2610 & 0,2615 & 0,2745 & 0,2461 \\
\hline Re & 2719 & 3107 & 3113 & 3268 & 2930 \\
\hline Tube no. & $\mathbf{1 6}$ & $\mathbf{1 7}$ & $\mathbf{1 8}$ & $\mathbf{1 9}$ & $\mathbf{2 0}$ \\
\hline $\begin{array}{c}\text { Flow rate } \\
{\left[\mathrm{m}^{3} / \mathrm{h}\right]}\end{array}$ & 0,2648 & 0,2526 & 0,2595 & 0,2596 & 0,2582 \\
\hline Re & 3152 & 3007 & 3089 & 3090 & 3074 \\
\hline
\end{tabular}

\section{CFD simulation}

CFD simulation are carried out to study the flow maldistribution in the fin-and-tube heat exchanger. The simulation is performed using the commercial software ANSYS CFX [15]. A sample mesh is shown in Figure 11.

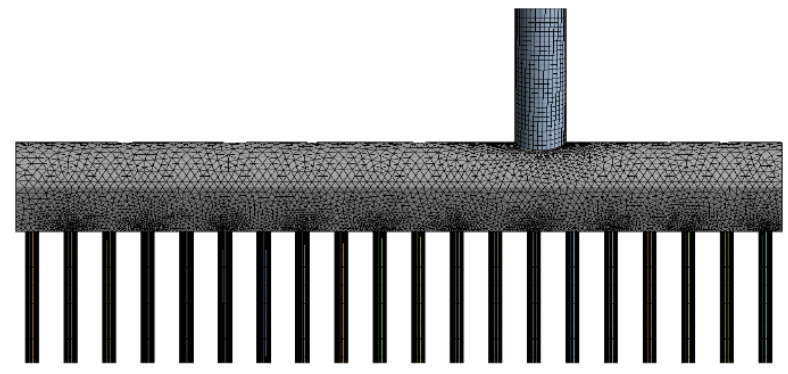

Fig. 11. Mesh used in CFD simulation.
A total volumetric flow rate is specified at the location of inlet nozzle pipe as inlet boundary condition in CFD simulation. At the location of outlet nozzle pipe, the outflow boundary condition with relative pressure set as 0 is given. The SSG Reynolds Stress Transport turbulence model is used to simulate the fluid flow of water in heat exchanger. The model allows to simulate the flow field with flow separation and secondary flows. A sample streamlines obtained for measurement no 1, are shown in Fig. 12.
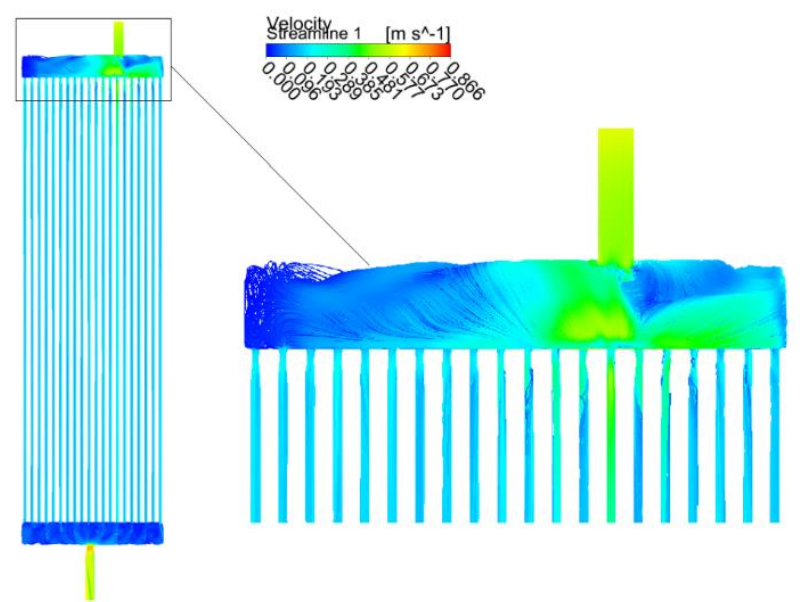

Fig. 12. Velocity streamlines obtained for total volumetric flow rate of $\dot{V}=3,0726\left[\mathrm{~m}^{3} / \mathrm{h}\right]$.

Figure 12 reveals the slightly higher value of flow velocity in tubes located downstream the inlet nozzle pipe. The comparison of volumetric flow rates in individual tubes is shown in Figures 13-17.

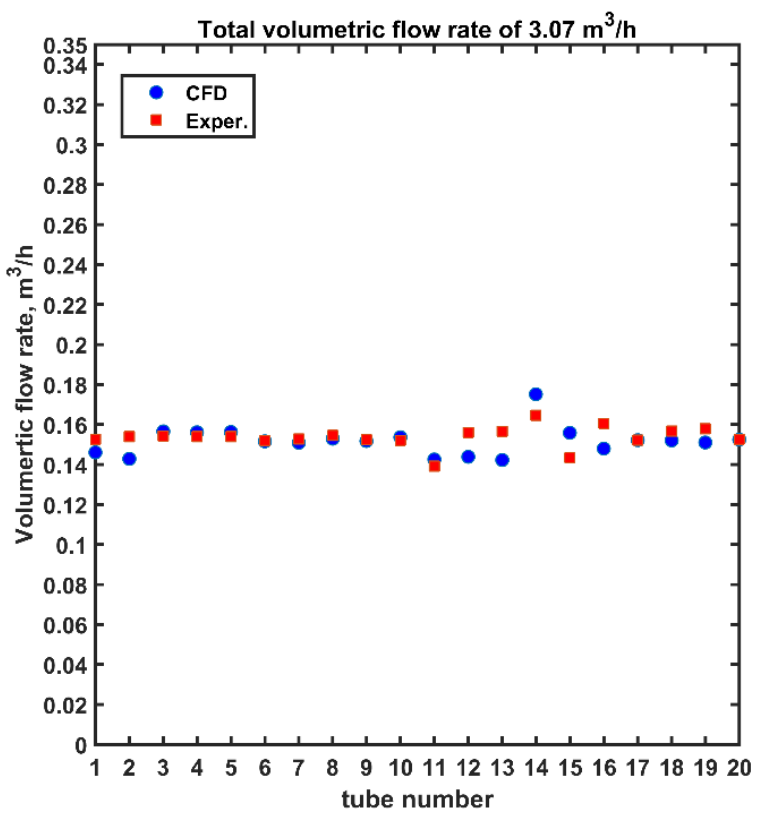

Fig. 13. Volumetric flow rate in heat exchanger tubes calculated using CFD and obtained from measurements for a total volumetric flow rate of $\dot{V}=3,07\left[\mathrm{~m}^{3} / \mathrm{h}\right]$. 


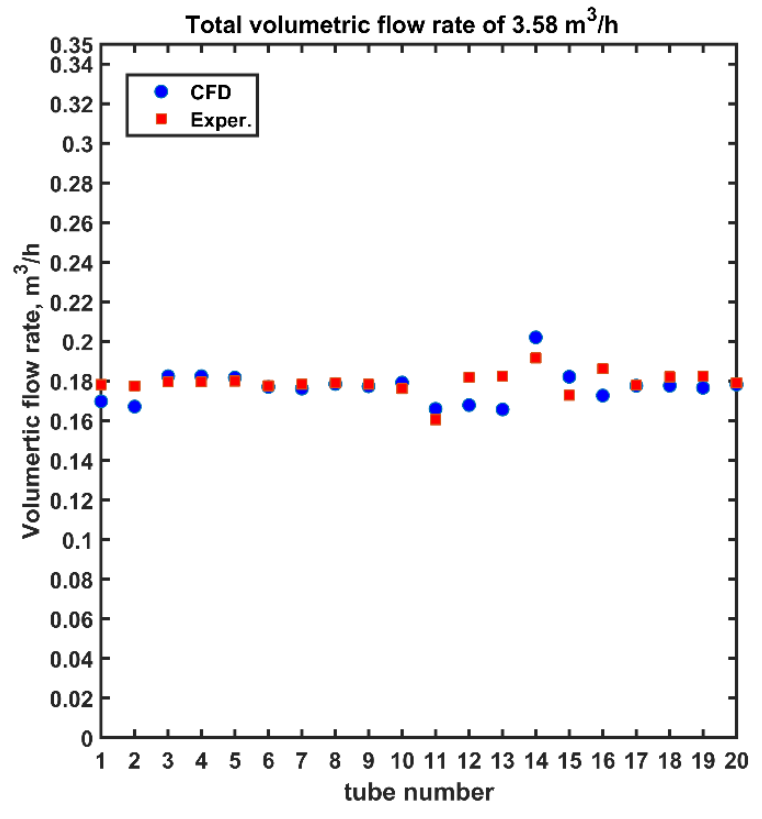

Fig. 14. Volumetric flow rate in heat exchanger tubes calculated using CFD and obtained from measurements for a total volumetric flow rate of $\dot{V}=3,58\left[\mathrm{~m}^{3} / \mathrm{h}\right]$.

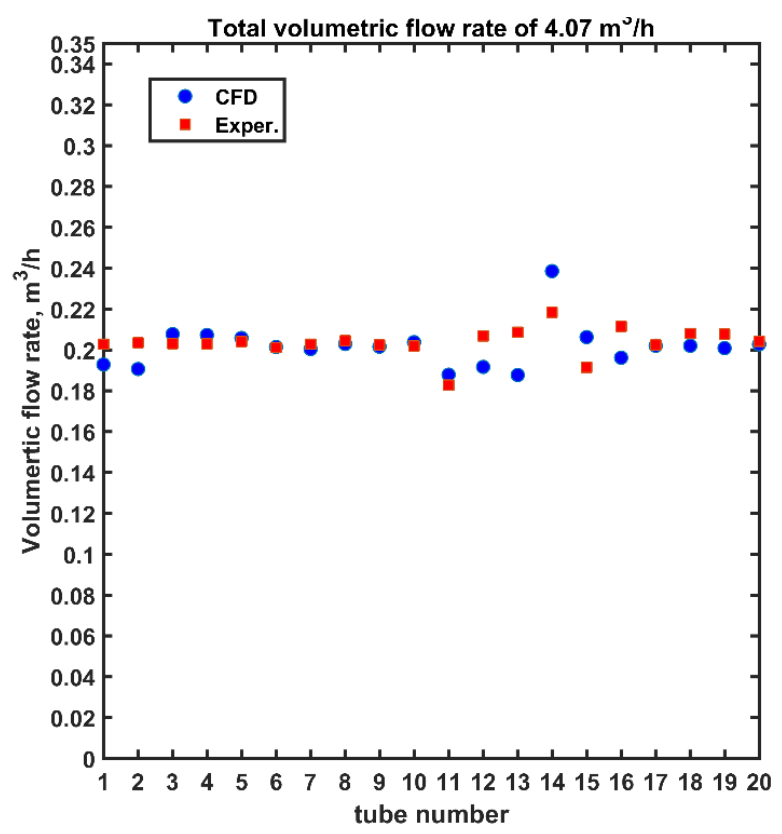

Fig. 15. Volumetric flow rate in heat exchanger tubes calculated using CFD and obtained from measurements for a total volumetric flow rate of $\dot{V}=4,07\left[\mathrm{~m}^{3} / \mathrm{h}\right]$.

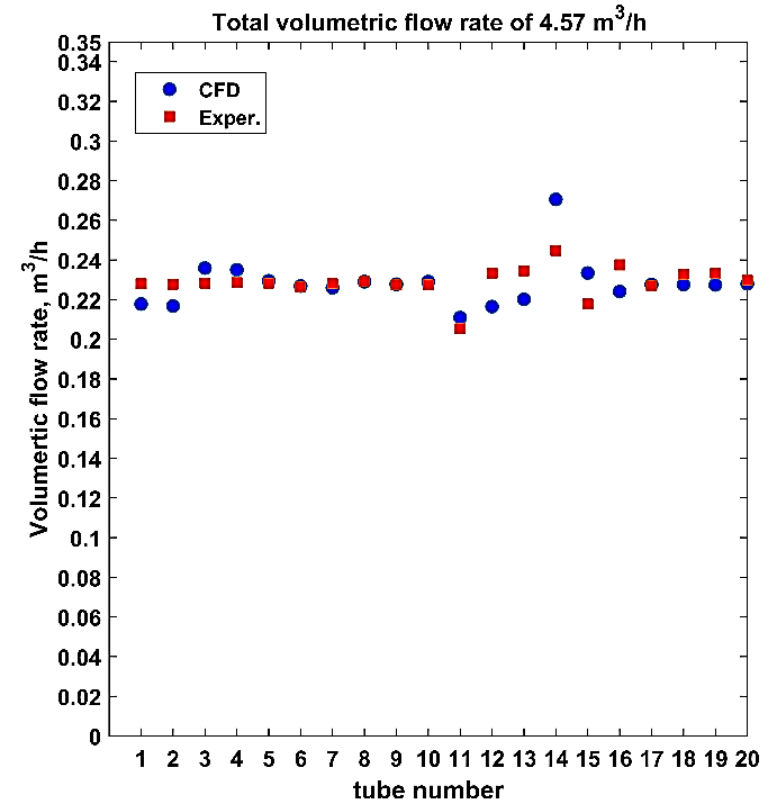

Fig. 16. Volumetric flow rate in heat exchanger tubes calculated using CFD and obtained from measurements for a total volumetric flow rate of $\dot{V}=4,57\left[\mathrm{~m}^{3} / \mathrm{h}\right]$.

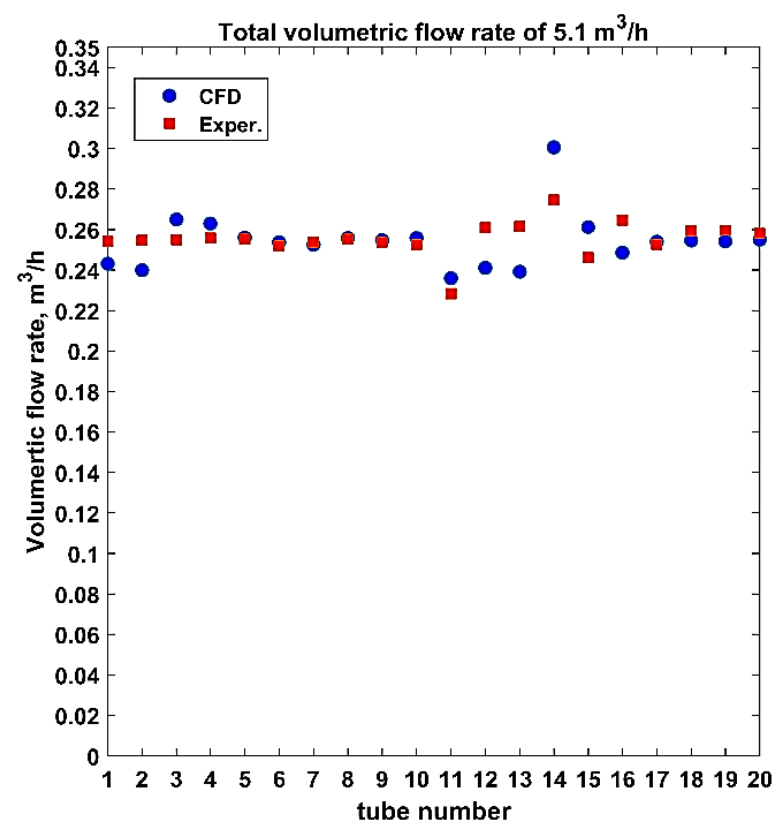

Fig. 17. Volumetric flow rate in heat exchanger tubes calculated using CFD and obtained from measurements for a total volumetric flow rate of $\dot{V}=5,1\left[\mathrm{~m}^{3} / \mathrm{h}\right]$.

Figure 13 shows the comparison between CFD simulation results and experimental data obtained for laminar flow regime where Re number varies in a range of 1600 to 1800 in heat exchanger tubes (measurement point no. 1). The CFD simulation results and experimental results are in good agreement; slight discrepancies are observed in a region downstream the inlet nozzle pipe, where the CFD simulation predicts the slightly higher value of flow rate in tube no. 14 (located directly below the inlet nozzle pipe), while the lower flow rates are calculated in tubes 12 and 13 nearby the inlet nozzle pipe. 
The similar situation occurs for other measurement points (Figs. 14-17), even for turbulent flow (measurement no. 5) where Re number exceeds 3000 . Therefore, for tube Re number from 1800-3100, the SSG Reynolds Stress Transport turbulence model provides satisfactory agreement with the measurement data.

\section{Conclusions}

This paper presents the experimental and numerical investigation of flow distribution in a single pass, double row tubular space of fin-and-tube heat exchanger. The elliptical tube bundle with tubes arranged in staggered formation is examined. The stand installed in the Institute of Thermal Power Engineering of the Cracow University of Technology allows one to measure a volumetric flow rate in all tubes of the heat exchanger. The Sontax Superstatic 749 ultrasonic flow meters are used for flow rate measurements. The measurements were performed for various inlet flow rates, so that the Re number in tubes was examined in a range of 1800 to 3100. In CFD simulation the SSG Reynolds Stress Transport turbulence model was used, and provided satisfactory agreement with the experimental data. The highest difference in measured and predicted flow rate occurs in a tube located downstream the inlet nozzle pipe, where the CFD simulation overpredicts the value of flow rate. In tubes located far from the inlet nozzle pipe, the measurement results and simulation results are in very good agreement.

\section{Acknowledgement}

The author would like to acknowledge the Polish National Science Center for a financial support. The computational results presented in this paper are the part of the research grant OPUS 6. The project was financed by the Polish National Science Centre awarded based on the decision number DEC2013/11/B/ST8/00340.

\section{References}

1. Łopata S., Ocłoń P. Archives of thermodynamics 31, 3, pp. 37-53 (2010)

2. Ocłoń P., Łopata S. Technical Transactions. Mechanics 4-M/2011/B, 7, year 108, pp. 391-400 (2011)

3. Ocłoń P. (PhD Thesis, Kraków ,(2013)

4. Łopata S., Ocłoń P., (Fluid Dynamics, Computational Modeling and Applications, edited by L. Hector Juarez, part 3, chapter 14, InTech, ISBN: 978-95351-0052-2, pp. 327 - 356, Croatia 2012)

5. Łopata S., Ocłoń P., Rynek Energii 102, 5, pp. 112124 (2012)

6. Łopata, S., Ocłoń, P., Nowak-Ocłoń, M. E3S Web of Conferences, 13, art. no. 02001 (2017)

7. Ocłoń, P., Łopata, S., Chłosta, K. Procedia Engineering, 157, pp. 428-435 (2016)

8. Łopata, S., Ocłoń, P. Energy, 92, pp. 100-116. (2015)
9. Ocłoń, P., Łopata, S., Nowak, M. Heat and Mass Transfer/Waerme- und Stoffuebertragung, 51 (4), pp. 553-566. (2015)

10. Ocłoń, P., Nowak, M., Łopata, S. Journal of Thermal Science, 23 (2), art. no. 1003-2169(2014)02-017710, pp. 177-186. (2014)

11. Ocłoń, P., Łopata, S., Nowak, M., Benim, A.C. Progress in Computational Fluid Dynamics, 15 (5), pp. 290-306. (2015)

12. Ocłoń, P., Łopata, S. Heat Transfer Engineering, 39 (13-14), pp. 1139-1155. (2018)

13. Taler, D., Ocłon, P. International Journal of Thermal Sciences, 84, pp. 309-322. (2014)

14. Taler, D., Ocłoń, P. Chemical Engineering and Processing: Process Intensification, 83, pp. 1-11. (2014)

15. ANSYS Inc, Ansys CFX Theory Reference Guide, 2016 